\title{
Evaluation of Cobalt-Labeled Octreotide Analogs for Molecular Imaging and Auger Electron-Based Radionuclide Therapy
}

\author{
Helge Thisgaard*1,2, Birgitte Brinkmann Olsen*1, Johan Hygum Dam ${ }^{1}$, Peter Bollen ${ }^{3}$, Jan Mollenhauer ${ }^{4}$, \\ and Poul Flemming Høilund-Carlsen ${ }^{1,2}$ \\ ${ }^{1}$ PET \& Cyclotron Unit, Department of Nuclear Medicine, Odense University Hospital, Odense, Denmark; ${ }^{2}$ Institute of Clinical \\ Research, University of Southern Denmark, Odense, Denmark; ${ }^{3}$ Biomedical Laboratory, University of Southern Denmark, Odense, \\ Denmark; and ${ }^{4}$ Lundbeckfonden Center of Excellence NanoCAN and Molecular Oncology Group, Institute for Molecular Medicine, \\ University of Southern Denmark, Odense, Denmark
}

\begin{abstract}
The somatostatin receptor, which is overexpressed by many neuroendocrine tumors, is a well-known target for molecular imaging and peptide receptor radionuclide therapy. Recently, ${ }^{57} \mathrm{Co}$-labeled DOTATOC, an octreotide analog, was shown to have the highest affinity yet found for somatostatin receptor subtype 2 . The aim of this study was to evaluate the biologic effects of novel cobalt-labeled octreotide analogs targeting the somatostatin receptor to identify promising candidates for molecular imaging and Auger electron-based radionuclide therapy. Methods: Cobalt-labeled DOTATATE, DOTATOC, and DOTANOC were prepared with ${ }^{57} \mathrm{Co}$ or ${ }^{58 \mathrm{~m} C o}$ for SPECT or Auger electron-based therapy, respectively. The cellular uptake and intracellular distribution of the radioligands were characterized with the pancreatic tumor cell line AR42J in vitro, including assessment of the therapeutic effects of ${ }^{58 \mathrm{~m} C o-}$ DOTATATE via DNA double-strand break and proliferation assays. Comparisons with the therapeutic effects of ${ }^{111} \mathrm{In}$ - and ${ }^{177}$ Lu-DOTATATE were also performed. Tumor uptake and normal tissue uptake were characterized in a subcutaneous pancreatic tumor mouse model. Results: All 3 cobalt-conjugated peptides resulted in time-dependent and receptor-specific uptake, with a high level ( $\geq 88 \%)$ of cellular internalization in vitro of the total cell-associated radioactivity. The DNA double-strand break yield showed a dose-dependent increase with activity, whereas cell survival showed a dose-dependent decrease. ${ }^{58 m}$ Co-DOTATATE was significantly more efficient in cell killing per cumulated decay than ${ }^{111} \mathrm{In}$ - and ${ }^{177}$ Lu-DOTATATE. The in vivo pharmacokinetic studies showed a high level of receptor-specific tumor uptake. Conclusion: All cobalt-labeled radioligands showed a high level of receptor-specific uptake both in vitro and in vivo in tumorbearing mice. Furthermore, ${ }^{58 \mathrm{~m} C o-D O T A T A T E}$ showed considerable therapeutic effects in vitro and, thus, could be an effective agent for eradicating disseminated tumor cells and micrometastases.
\end{abstract}

Key Words: Auger electrons; radionuclide therapy; DOTATATE; ${ }^{58 \mathrm{~m} C o} ;{ }^{177} \mathrm{Lu}$

J Nucl Med 2014; 55:1311-1316

DOI: $10.2967 /$ jnumed.114.137182

Received Jan. 6, 2014; revision accepted Apr. 9, 2014.

For correspondence or reprints contact: Helge Thisgaard, Department of Nuclear Medicine, Odense University Hospital, Sønder Boulevard 29, DK5000 Odense, Denmark.

E-mail: Helge.Thisgaard@rsyd.dk

${ }^{*}$ Contributed equally to this work.

Published online May 29, 2014.

COPYRIGHT (c) 2014 by the Society of Nuclear Medicine and Molecular Imaging, Inc.
$\mathbf{T}$ he somatostatin receptor, which is overexpressed by many neuroendocrine tumors, is a well-known target for molecular imaging (i.e., PET and SPECT) and for peptide receptor radionuclide therapy $(1,2)$. One of the most widely used radiopharmaceuticals for SPECT imaging of these tumors is ${ }^{111}$ In-diethylenetriaminepentaacetic acid (DTPA)-D-Phe ${ }^{1}$-octreotide (OctreoScan; Mallinckrodt), which was developed from the somatostatin analog octreotide. Several modifications of this peptide have been made over time, leading to new generations of the ligand with improved binding to somatostatin receptor-positive tissues - for example, DOTATOC (DOTA-[Tyr ${ }^{3}$ ]octreotide) (3), DOTATATE (DOTA-[Tyr $\left.{ }^{3}, \mathrm{Thr}^{8}\right]$-octreotide) (4), and DOTANOC (DOTA-[1-Nal $\left.{ }^{3}\right]$-octreotide) (5).

Recently, ${ }^{57}$ Co-labeled DOTATOC was shown to have the highest affinity yet found for the somatostatin receptor subtype 2 (SSTR2) (6). Furthermore, the rate of internalization of this compound into the pancreatic tumor cell line AR42J was the highest found for any somatostatin-based radioligand. In a study by Uusijärvi et al. (7) of 59 therapeutic radionuclides ( $\alpha, \beta$, and Auger electron emitters), the Auger electron emitter ${ }^{58 \mathrm{~m}} \mathrm{Co}$ was the radionuclide that resulted in the second highest theoretic tumor-to-normal tissue dose rate ratio. Therefore, the therapeutic potency of the ${ }^{58 \mathrm{~m}} \mathrm{Co}$ radionuclide and the remarkable obtainable internalization rates and affinities for SSTR2-expressing tumor cells make ${ }^{58 \mathrm{~m}}$ Co-labeled octreotide analogs attractive candidates for targeted Auger electron-based therapy of small somatostatin receptor-positive tumors and micrometastases.

The purpose of this study was to evaluate the biologic effects of selected cobalt-labeled octreotide analogs targeting the somatostatin receptor to identify promising candidates for molecular imaging and Auger electron-based radionuclide therapy.

\section{MATERIALS AND METHODS}

\section{Cell Culture}

The rat pancreatic tumor cell line AR42J (CLS Cell Lines Service $\mathrm{GmbH}$ ), which expresses SSTR2, was grown in complete medium (Nutrients Mixture F-12 Ham [Sigma-Aldrich] supplemented with 10\% fetal bovine serum [Life Technologies], $1 \%$ penicillin/streptomycin [Sigma-Aldrich], and $2 \mathrm{mM}$ L-glutamine [Sigma-Aldrich]). The cells were maintained in a humidified $5 \% \mathrm{CO}_{2}$ atmosphere at $37^{\circ} \mathrm{C}$.

\section{Chemicals and Syntheses}

All solvents and reagents were used as received unless otherwise noted. Water was deionized with a Millipore Direct-Q 3 ultraviolet water 
purification system. DOTATOC was obtained from JPT Peptide Technologies and exhibited a purity of greater than $99.5 \%$. DOTATATE and DOTANOC were obtained from ABX and exhibited a purity of greater than $99 \%$. Sodium acetate buffer for complexometry ( $\mathrm{pH} 4.6$; SigmaAldrich) was applied for labeling. The $\gamma$ spectra were measured by use of a calibrated broad-energy germanium detector (BEGE2020-7600SL; Canberra) with detector software Genie 2000 (version 3.2.1; Canberra) and the nuclear data shown in Table 1.

Cobalt-labeled DOTATATE, DOTATOC, and DOTANOC were prepared with ${ }^{57} \mathrm{Co}$ for assessment of the biokinetics of the radioligands in vitro and in vivo, and ${ }^{58 \mathrm{~m}} \mathrm{Co}$-labeled DOTATATE was used for Auger electron-based radionuclide therapy. ${ }^{57} \mathrm{Co}$ was purchased as ${ }^{57} \mathrm{CoCl}_{2}$ from Perkin Elmer. ${ }^{58 \mathrm{~m}} \mathrm{Co}$ activity was produced and the activity was measured from the coproduced ${ }^{58 \mathrm{~g}} \mathrm{Co}$ as previously described (8) with irradiation times of up to $6 \mathrm{~h}$. An additional purification step was added to increase the specific activity of the labeled peptide. In brief, the additional purification step was performed with a Chromafix 30-PS- $\mathrm{HCO}_{3}$ cartridge (45 mg; Macherey-Nagel) that had been conditioned with $5 \mathrm{~mL}$ of $4 \mathrm{M} \mathrm{HCl}$. The radiocobalt solution was eluted through the cartridge, and then the cartridge was washed with $0.2 \mathrm{~mL}$ of $4 \mathrm{M} \mathrm{HCl}$ to completely remove the cobalt. The solution $(0.5 \mathrm{~mL})$ was evaporated to dryness and redissolved in $0.3 \mathrm{~mL}$ of $0.04 \mathrm{M} \mathrm{HCl}$ for labeling. Sodium acetate buffer $(30-50 \mu \mathrm{L} ; \mathrm{pH} 4.6)$, water (for injection; $75 \mu \mathrm{L}$; Braun), DOTA-peptide (5-250 $\mu \mathrm{g}$ ), and the radionuclide in $0.04-0.05 \mathrm{M} \mathrm{HCl}$ were loaded into a small glass vial and heated at $85^{\circ} \mathrm{C}$ in a water bath for $30 \mathrm{~min}$.

For comparison purposes, ${ }^{111}$ In-DOTATATE was prepared with the same labeling conditions as those used for cobalt, but ${ }^{177} \mathrm{Lu}-$ DOTATATE was prepared as described by Kwekkeboom et al. with minor deviations (4). In brief, a kit consisting of DOTATATE $(0.25 \mathrm{mg})$, sodium ascorbate $(125 \mathrm{mg})$, gentisic acid $(25 \mathrm{mg})$, and water (for injection; $0.80 \mathrm{~mL}$ ) was added to ${ }^{177} \mathrm{Lu}$ (in $0.04 \mathrm{M} \mathrm{HCl}$; $0.200 \mathrm{~mL} ; 7.6 \mathrm{GBq})$. The solution was heated in a water bath at $85^{\circ} \mathrm{C}$ for $30 \mathrm{~min}$, and $1 \mathrm{~mL}$ of DTPA $(2 \mathrm{mg} / \mathrm{mL}$ in isotonic saline) was added. The labeling yield and the radiochemical purity were always greater than $99 \%$. ${ }^{111} \mathrm{In}$ was purchased as ${ }^{111} \mathrm{InCl}_{3}$ from Dupharma, and ${ }^{177} \mathrm{Lu}$ was purchased as ${ }^{177} \mathrm{LuCl}_{3}$ from ITG Isotope Technologies.

Radiochemical purity was assessed by use of analytic reverse-phase high-performance liquid chromatography with a Hitachi LaChrom Elite system and a Phenomenex Jupiter C18 300A column $(150 \times 4.60 \mathrm{~mm}$; $5 \mu \mathrm{m})$. The following eluents were applied: $\mathrm{H}_{2} \mathrm{O}$ with $0.1 \%$ trifluoroacetic acid (eluent $\mathrm{A}$ ) and acetonitrile (eluent $\mathrm{B}$ ). The following program was used: $86 \%$ eluent $\mathrm{A}$ and $14 \%$ eluent $\mathrm{B}$ for $0-2$ min, $86 \%$ eluent $\mathrm{A}$ and $14 \%$ eluent $B$ to $37 \%$ eluent $A$ and $63 \%$ eluent $B$ for $2-10$ min, and $37 \%$ eluent $A$ and $63 \%$ eluent $B$ to $86 \%$ eluent $A$ and $14 \%$ eluent $B$ for $10-12 \mathrm{~min}$ at a flow of $1 \mathrm{~mL} / \mathrm{min}$. The retention times were approximately
$2.2 \mathrm{~min}$ for unbound radiometal and approximately $8.2 \mathrm{~min}$ for radiometal-DOTA-peptide.

\section{Subcellular Distribution and Efflux}

AR42J cells were seeded in 6-well plates (400,000 cells per well) $48 \mathrm{~h}$ before the experiment. On the day of the experiment, the cells were washed twice with incubation medium (1\% bovine serum albumin in serum-free Nutrients Mixture F-12 Ham). The cells were incubated with ${ }^{57}$ Co-labeled peptide or ${ }^{111} \mathrm{In}$-DOTATATE at $0.02 \mathrm{MBq} / \mathrm{mL}$ (specific activity, 3-4 MBq/nmol) in incubation medium with or without an excess of octreotide (Sequoia Research Products) at $37^{\circ} \mathrm{C}$ for various times. Cellular uptake was stopped by removal of the incubation medium, and the cells were washed 3 times with cold phosphatebuffered saline. For removal of receptor-bound radioligand, the cells were incubated for $5 \mathrm{~min}$ in ice-cold acid wash buffer $(0.2 \mathrm{M}$ sodium acetate, $0.5 \mathrm{M} \mathrm{NaCl} ; \mathrm{pH} 2.5$ ) on ice (9). The cells were separated into cytoplasmic and nuclear fractions with a Nuclei EZ Prep nuclei isolation kit (Sigma-Aldrich) in accordance with the manufacturer's instructions. The radioactivity of the incubation medium and the receptor-bound, cytoplasmic, and nuclear fractions was measured with a 2470 Wizard Automatic $\gamma$ Counter (Perkin Elmer).

For efflux studies, cellular uptake was stopped after $2 \mathrm{~h}$ by removal of the incubation medium. Unbound radioactivity was removed by washing the cells 3 times with cold phosphate-buffered saline, and receptor-bound activity was removed as described earlier. The cells were washed with incubation medium and returned to the incubator with fresh incubation medium. At various times, the medium was collected and replaced with fresh incubation medium. Thereafter, the cells were incubated with $1 \mathrm{M} \mathrm{NaOH}$ to extract the remaining cellassociated radioligand. The radioactivity of the incubation medium and the receptor-bound, external, and internal fractions was measured with the 2470 Wizard Automatic $\gamma$ Counter.

\section{Assessment of Yield of DNA Double-Strand Breaks from ${ }^{58 m}$ Co-, ${ }^{111}$ In-, or ${ }^{177}$ Lu-DOTATATE}

AR42J cells were washed 3 times with incubation medium and incubated with radioligand at $0-50 \mathrm{MBq} / \mathrm{mL}$ (specific activity, 44-84 $\mathrm{MBq} / \mathrm{nmol}$ ) for $1 \mathrm{~h}$ at $37^{\circ} \mathrm{C}$ with or without an excess of octreotide. The cells were subsequently fixed with $4 \%$ paraformaldehyde and permeabilized with $0.2 \%$ Triton X-100 (Dow Chemical Co.). DNA double-strand breaks (DSBs) were visualized by incubating the cells with rabbit polyclonal anti-phospho-H2AX (P-Ser139) antibody (Sigma-Aldrich) and then with AlexaFluor-conjugated goat antirabbit antibody (Life Technologies). The cells were counterstained with 4', 6-diamidino-2-phenylindole (Sigma-Aldrich) and analyzed with an Olympus FV1000 confocal laser scanning microscope. $\gamma \mathrm{H} 2 \mathrm{AX}$ foci (from $>30$ cells for each activity concentration) were analyzed with FociCounter analysis software (10).

TABLE 1

Nuclear Data for Radioisotopes Used in This Work (21)

\begin{tabular}{lccc}
\hline Isotope & Half-life & Decay mode $^{*}$ & Major y lines $(\mathrm{keV})^{*}$ \\
\hline${ }^{57} \mathrm{Co}$ & $271.8 \mathrm{~d}$ & EC $(100)$ & $122.1(85.6), 136.5(10.7)$ \\
${ }^{589} \mathrm{Co}$ & $70.86 \mathrm{~d}$ & EC $(85.1)+\beta^{+}(14.9)$ & $810.8(99)$ \\
${ }^{58 \mathrm{~m}} \mathrm{Co}$ & $9.04 \mathrm{~h}$ & IT $(100)$ & $24.9(0.0389)$ \\
${ }^{111} \mathrm{In}$ & $2.80 \mathrm{~d}$ & EC $(100)$ & $171.3(90), 245.4(94)$ \\
${ }^{177} \mathrm{Lu}$ & $6.73 \mathrm{~d}$ & $\beta^{-}(100)$ & $112.9(6.4), 208.4(11.0)$
\end{tabular}

*Values in parentheses represent percentage abundance.

$\mathrm{EC}=$ electron capture; IT = internal transition. 


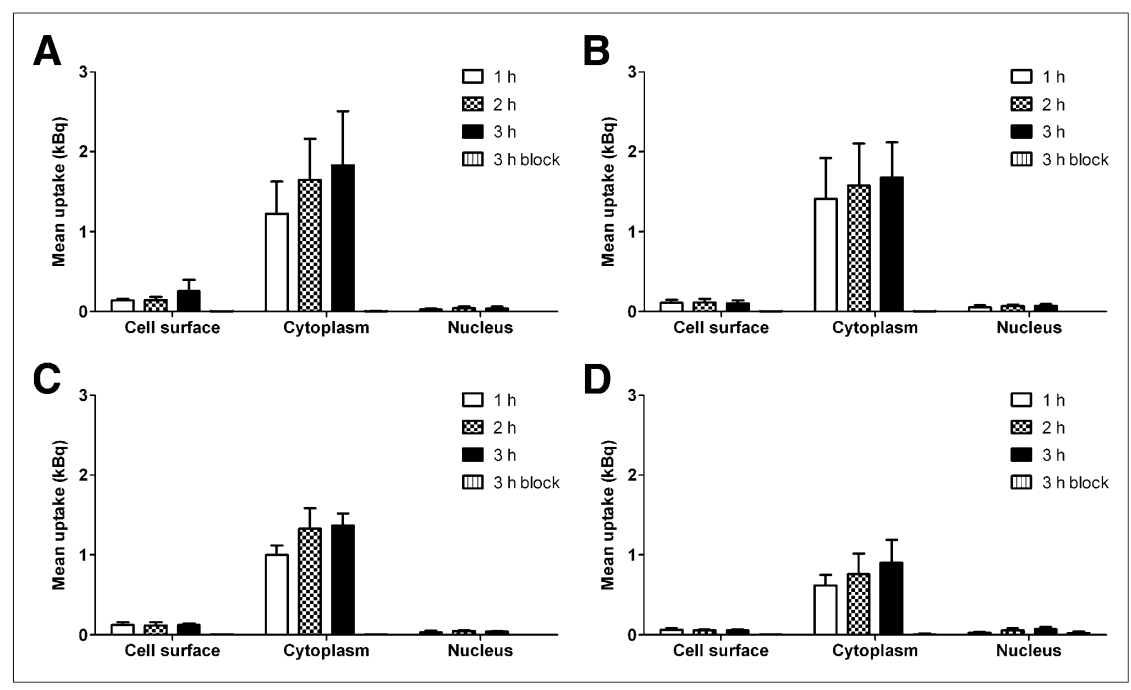

FIGURE 1. Subcellular distributions of cobalt-labeled peptides ${ }^{57} \mathrm{Co}$-DOTATOC (A), ${ }^{57} \mathrm{Co}-$ DOTANOC (B), ${ }^{57}$ Co-DOTATATE (C), and ${ }^{111}$ In-DOTATATE (D) in pancreatic cancer cell line AR42J as function of increasing incubation times (1-3 h). For each radiopharmaceutical, receptorblocking experiment was performed with excess octreotide (" $3 \mathrm{~h}$ block"). Data are mean \pm SD from triplicate experiments.

\section{Antiproliferative Effects of ${ }^{58 m} \mathrm{Co}-,{ }^{111}$ In-, or ${ }^{177}$ Lu-DOTATATE}

AR42J cells were seeded in 96-well plates (5,000 cells per well); $24 \mathrm{~h}$ later, the cells were washed 3 times with incubation medium and then incubated with radioligand at $0-50 \mathrm{MBq} / \mathrm{mL}$ (specific activity, 44-84 $\mathrm{MBq} / \mathrm{nmol}$ ) with or without an excess of octreotide for $24 \mathrm{~h}$. On the next day, the cells were washed 3 times with phosphate-buffered saline and then incubated in complete medium for $7 \mathrm{~d}$. The WST-1 (Roche Applied Science) assay was performed in accordance with the manufacturer's instructions.

\section{In Vivo Animal Studies}

Female Swiss nude mice (NTac:NIHS-Foxn $1^{n u}$; Taconic) and C.B17 SCID mice (C.B-Igh-1 ${ }^{b} /$ IcrTac-Prkdscid; Taconic), 6-10 wk old, were anesthetized with isoflurane in $100 \%$ oxygen. Next, the mice were inoculated in the right flank with $10^{6}$ AR42J cells that had been prepared in $50 \mu \mathrm{L}$ of medium containing extracellular matrix gel (Sigma-Aldrich; ratio, 1:1). Tumors were allowed to grow for 10-14 d, reaching a weight of $67-422 \mathrm{mg}$. All animal experiments were approved by The Animal Experiments Inspectorate in Denmark.

Studies of the biodistribution of ${ }^{57} \mathrm{Co}$-DOTATATE in tumor-bearing C.B-17 SCID mice were performed with $105 \pm 18 \mathrm{kBq}$ (mean \pm SD) of the tracer ( $32 \pm 5 \mathrm{pmol}$ of peptide in $0.1 \%$ bovine serum albumin) injected retroorbitally into the venous sinus of anesthetized mice (11). At various times after injection of the tracer, the mice $(n=3$ in each group) were euthanized and dissected. Organs were collected and weighed, and activities were measured with the 2470 Wizard Automatic $\gamma$ Counter. The $\gamma$ counter was cross-calibrated with the Ge detector used to determine the injected activities. Organ tracer activity distributions were determined as the percentage injected activity per gram of tissue.

SPECT/CT scans of AR42J tumor-bearing Swiss nude mice (inoculated as described earlier) were performed with a Siemens Inveon small-animal scanner. The animals were anesthetized with isoflurane in $100 \%$ oxygen and then injected intravenously with ${ }^{57} \mathrm{Co}$-DOTATATE or ${ }^{57} \mathrm{Co}$-DOTATOC (5.5-7.8 MBq; $\left.1-4 \mathrm{nmol}\right)$. At various times after injection, the animals were scanned. Before the last scan, at $4 \mathrm{~h}$ after injection, the animals were euthanized to prevent further redistribution of the radioligand during the rather long SPECT scan (up to $280 \mathrm{~min}$ ) at this time point. A receptor-blocking experiment was performed by coinjecting $0.93 \mu \mathrm{mol}$ of octreotide intraperitoneally with the radioligand to visualize nonspecific binding. The SPECT scans were performed with pinhole collimators (two $5 \times 1.0 \mathrm{~mm}$ ) and acquisition times of 10-280 min. The images were reconstructed with the 3-dimensional ordered-subset maximization expectation algorithm. The CT scans were performed with $80-\mathrm{kVp}$ x-rays $(500 \mu \mathrm{A})$, a rotation of $360^{\circ}$, and 360 projections.

\section{Statistical Analysis}

Data were analyzed with unpaired, 2-tailed Student $t$ tests. The $F$ test was used to compare best-fit curves of the survival data as a function of cumulated decays with GraphPad Prism (GraphPad Software, Inc.). A $P$ value of less than 0.05 was considered statistically significant.

\section{RESULTS}

Up to $0.58 \mathrm{GBq}$ of therapeutic ${ }^{58 \mathrm{~m}} \mathrm{Co}-$ DOTATATE was produced with a specific activity of up to $84 \mathrm{MBq} / \mathrm{nmol}$. The radionuclide and radiochemical purities of ${ }^{58 \mathrm{~m}} \mathrm{Co}-$ DOTATATE were always greater than $98 \%$ and $99 \%$, respectively, at the end of synthesis - the former due to the inevitable coproduction of the ground state of ${ }^{58} \mathrm{Co}$.

The subcellular distributions of the cobalt-labeled peptides and, for comparison purposes, of the Auger electron-emitting compound ${ }^{111}$ In-DOTATATE in the pancreatic cancer cell line AR42J as a function of increasing incubation times are shown in Figure 1. All 3 cobalt-labeled peptides resulted in time-dependent uptake, with a high level $(\geq 88 \%)$ of cellular internalization in vitro of the total cell-associated radioactivity. Similar internalization was found for ${ }^{111}$ In-DOTATATE. Moreover, the uptake was receptorspecific, because an excess of octreotide could block the internalization. The overall level of radioligand uptake was significantly higher (49\%-123\% higher) for the cobalt-labeled peptides than for ${ }^{111}$ In-DOTATATE at all time points. However, only $2 \%-4 \%$ of the cell-associated cobalt activity was transferred to the cell nuclei, where Auger electrons are most effective for cell killing regardless of the peptide used, whereas $4 \%-7 \%$ nucleus translocation was seen with ${ }^{111}$ In-DOTATATE.

For determination of the retention of the cobalt-labeled peptides in the cells, the rates of externalization of the intracellular radioactivity (efflux) after $2 \mathrm{~h}$ of preloading were measured for the 3 cobalt-labeled peptides and for ${ }^{111}$ In-DOTATATE (results not shown). The externalization rates were similar for the 4 radioligands tested. Of the cobalt-labeled peptides, ${ }^{57} \mathrm{Co}$-DOTATATE showed the highest level of retention in the cells $(41 \% \pm 5 \%$ at $24 \mathrm{~h}),{ }^{57} \mathrm{Co}$-DOTANOC showed the lowest level of retention $(33 \% \pm 7 \%$ at $24 \mathrm{~h})$, and ${ }^{57}$ Co-DOTATOC retained $37 \% \pm 3 \%$ at $24 \mathrm{~h}$. For comparison ${ }^{111} \mathrm{In}$-DOTATATE retained $45 \% \pm 5 \%$ at $24 \mathrm{~h}$ (decay corrected). Between $64 \%$ and $73 \%$ of the internalized ${ }^{57} \mathrm{Co}$ or ${ }^{111}$ In activities were still retained in the cells after $4 \mathrm{~h}$.

The formation of DNA DSBs showed a clear dose-dependent increase with activity for both ${ }^{58 \mathrm{~m} C o-D O T A T A T E}$ and ${ }^{111} \mathrm{In}$ DOTATATE (Fig. 2). The effect could be strongly diminished by blocking the somatostatin receptors with excess octreotide. For comparison, the DSB yield was also measured for the $\beta^{-}$-emitting ${ }^{177} \mathrm{Lu}$-DOTATATE, which is currently among the best radioligands 


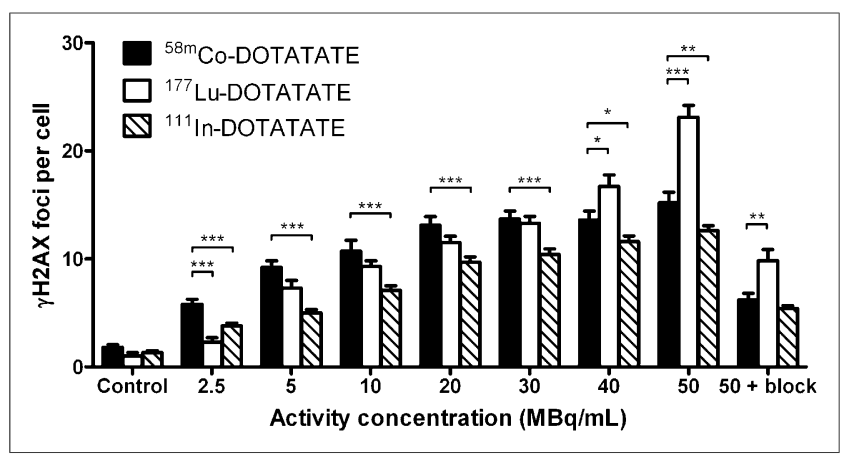

FIGURE 2. Formation of DNA DSBs in AR42J cells exposed for $1 \mathrm{~h}$ to increasing amounts of ${ }^{58 \mathrm{~m}} \mathrm{Co}-,{ }^{111} \mathrm{In}$-, and ${ }^{177} \mathrm{Lu}$-DOTATATE activities (mean \pm SEM). Nonspecific toxicity at $50 \mathrm{MBq} / \mathrm{mL}$ was assessed by blocking somatostatin receptors with excess octreotide ("50 + block"). $P$ values were determined with 2 -tailed Student $t$ test. ${ }^{*} P<0.05$. ${ }^{* *} P<$ $0.01 .{ }^{\star \star \star} P<0.001$.

for peptide receptor radionuclide therapy in patients (2). At the lowest activity concentration used, ${ }^{58 \mathrm{~m}} \mathrm{Co}$-DOTATATE resulted in the highest DSB yield of the tested compounds $(P<0.001)$. At the highest activity concentration, ${ }^{177} \mathrm{Lu}$-DOTATATE resulted in the highest DSB yield, but this radioligand also resulted in the highest nonspecific toxicity with blocked receptors $(P<0.01) .{ }^{111}$ In-DOTATATE showed low nonspecific toxicity comparable to that of ${ }^{58 \mathrm{~m} C o-}$ DOTATATE but was significantly less efficient in causing DSBs at all activity concentrations (Fig. 2).

The antiproliferative effects of ${ }^{58 \mathrm{~m}} \mathrm{Co}-,{ }^{111} \mathrm{In}-$, and ${ }^{177} \mathrm{Lu}-$ DOTATATE are shown in Figure 3. All radioligands resulted in a dose-dependent decrease in cell survival that could be strongly diminished by blocking the receptors with excess octreotide. At activity concentrations of less than or equal to $30 \mathrm{MBq} / \mathrm{mL}$, ${ }^{58 \mathrm{~m}} \mathrm{Co}$-DOTATATE showed a general trend to be more effective. Because the half-lives of the 3 therapeutic isotopes are different $\left.{ }^{(58 \mathrm{~m} C o}, 9.04 \mathrm{~h} ;{ }^{111} \mathrm{In}, 2.80 \mathrm{~d} ;{ }^{177} \mathrm{Lu}, 6.73 \mathrm{~d}\right)$, the numbers of cumulated decays from the radiopharmaceuticals during the cell survival experiments also were different. Therefore, a calculation was performed to determine the cumulated decays during the 24-h period of incubation with the radioligands. The cell survival as a function of the cumulated decays from the radiopharmaceuticals during this period is shown in Figure 4. The data indicated that ${ }^{58 \mathrm{~m} C o-D O T A T A T E}$ was significantly more efficient in cell killing per cumulated decay than the other radioligands.

For determination of the in vivo pharmacokinetics of cobaltlabeled DOTATATE, biodistribution and SPECT/CT studies of ${ }^{57} \mathrm{Co}$-DOTATATE $\left({ }^{57} \mathrm{Co}\right.$ was used as a surrogate for ${ }^{55} \mathrm{Co}$ for PET) in a pancreatic tumor-bearing mouse model were performed. ${ }^{57} \mathrm{Co}-$ DOTATATE showed a high level of receptor-specific uptake in the tumors (Fig. 5A). Figure 5B shows the nonspecific uptake achieved by blocking the somatostatin receptors with a coinjection of excess octreotide; the radioligand was found mainly in the kidneys, the main route of excretion for somatostatin analogs.

The biodistribution of ${ }^{57} \mathrm{Co}$-DOTATATE is shown in Figure 6 (as percentage injected activity per gram of tissue). A rapid, high level of uptake of ${ }^{57} \mathrm{Co}$-DOTATATE was observed in the tumors, but a moderate to high level of uptake (as percentage injected activity per gram of tissue) also was found in the somatostatin receptor-positive organs (pancreas, stomach, lungs, and adrenal glands) and in the kidneys because of excretion. However, when measured as the percentage injected activity, the highest overall

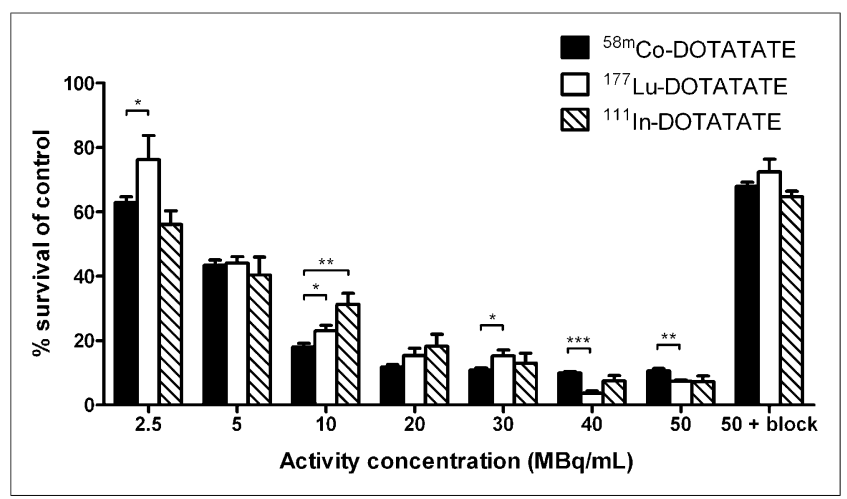

FIGURE 3. Antiproliferative effects in AR42 $\mathrm{J}$ cells exposed for $24 \mathrm{~h}$ to increasing amounts of ${ }^{58 \mathrm{~m} C o-},{ }^{111} \mathrm{In}$-, and ${ }^{177} \mathrm{Lu}$-DOTATATE activities. Nonspecific toxicity at $50 \mathrm{MBq} / \mathrm{mL}$ was assessed by blocking somatostatin receptors with excess octreotide (" 50 + block"). Data are mean \pm SEM from 5 replicate experiments. $P$ values were determined with 2-tailed Student $t$ test. ${ }^{\star} P<0.05$. ${ }^{\star \star} P<0.01$. ${ }^{\star \star \star} P<0.001$.

tissue activity at $4 \mathrm{~h}$ and $24 \mathrm{~h}$ after injection was found in the tumors. Tumor uptake between $4 \mathrm{~h}$ and $24 \mathrm{~h}$ decreased only to about $43 \%$, in good agreement with our in vitro efflux results. Clearance from the blood and the somatostatin receptor-negative tissues also was fast. The tumor-to-kidney, tumor-to-liver, and tumor-to-blood ratios at $4 \mathrm{~h}$ and $24 \mathrm{~h}$ after injection were 1.3$1.4,33-52$, and 121-137, respectively.

\section{DISCUSSION}

The development of novel radiopharmaceuticals for targeted radionuclide therapy of cancer is a rapidly growing research area (12). Most emerging radiopharmaceuticals consist of commercially available radionuclides bound to new targeting ligands. Fewer studies develop and test novel therapeutic radionuclides and address the consequences of changing the radionuclide to a putative therapeutically more potent one. As shown in Figure 1, it was possible to obtain a considerably higher level of receptormediated uptake in the pancreatic cancer cell line AR42J, which exclusively expresses SSTR2, by labeling DOTATATE with cobalt instead of indium at the same specific activity. This finding was in good agreement with the measured affinities for DOTATOC labeled with cobalt, gallium, or yttrium, as reported by Heppeler et al. (6); in that study, ${ }^{57} \mathrm{Co}$-DOTATOC resulted in the highest affinity for SSTR2. The authors concluded that ${ }^{57} \mathrm{Co}$-DOTATOC had

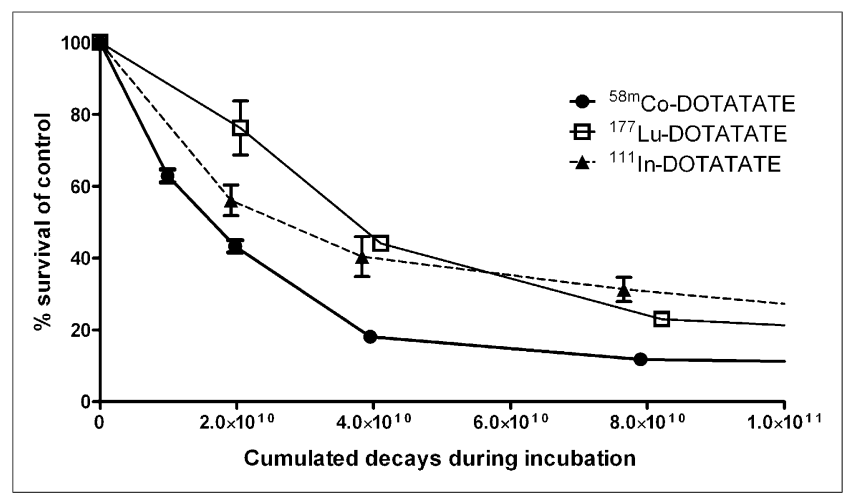

FIGURE 4. Antiproliferative effects in AR42J cells as function of number of cumulated decays during 24-h incubation with increasing amounts of ${ }^{58 \mathrm{~m} C o-}$, ${ }^{111} \mathrm{In}-$, and ${ }^{177} \mathrm{Lu}$-DOTATATE. 


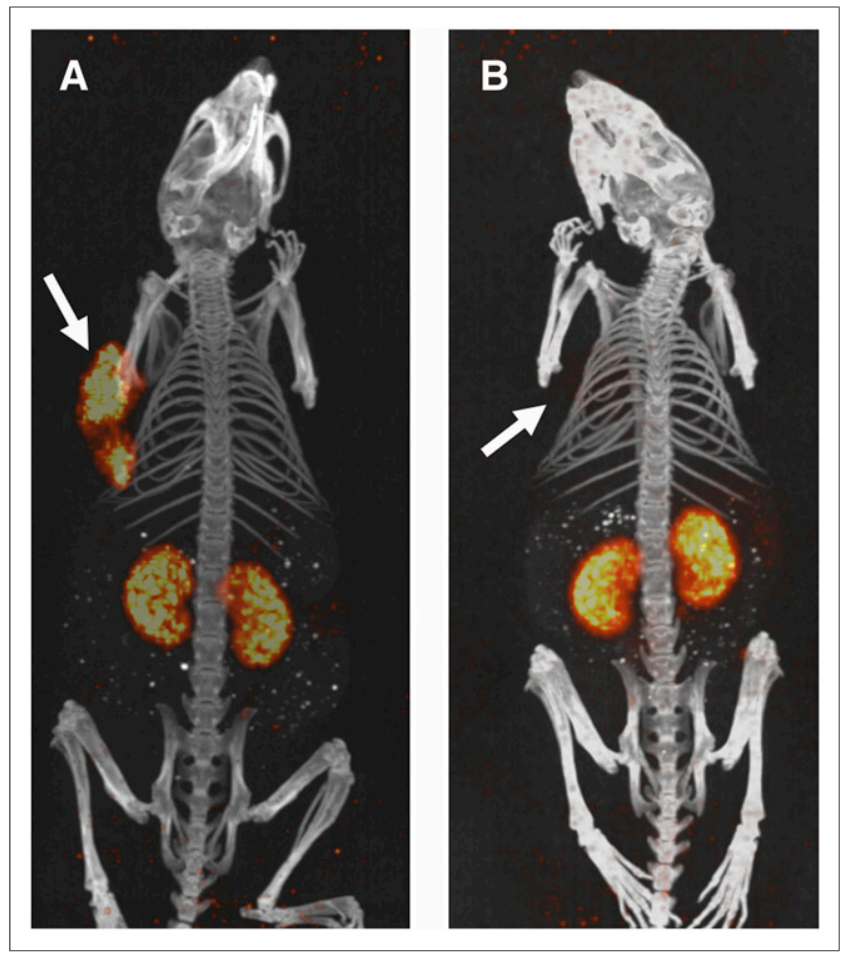

FIGURE 5. Maximum-intensity-projection images from SPECT/CT scans of AR42J tumor-bearing mice injected with $5.5-7.8 \mathrm{MBq}$ of ${ }^{57}$ Co-DOTATATE (1-4 nmol of peptide) and without (A) or with (B) coinjection of $0.93 \mu \mathrm{mol}$ of octreotide to visualize nonspecific binding or localization. Scans were performed at $4 \mathrm{~h}$ after injection. Arrows indicate locations of tumors.

the highest SSTR2 affinity of any somatostatin-based radioligand found so far. However, in the present study, the relative subcellular distributions of the cell-associated radioactivity in the pancreatic cancer cell line were similar for the 2 radiometals (Fig. 1).

As mentioned earlier, the retention and externalization (efflux) of the radiometals from AR42J tumor cells after incubation with the 3 cobalt-labeled peptides and ${ }^{111}$ In-DOTATATE were rather similar. The measured retention of ${ }^{57} \mathrm{Co}$-DOTATOC $(\sim 67 \%)$ at $4 \mathrm{~h}$ was in good agreement with that in the study of Heppeler et al. (6), who found that about $60 \%$ of ${ }^{57} \mathrm{Co}$-DOTATOC was retained after $4 \mathrm{~h}$. However, they also found rapid tumor clearance in vivo in an AR42J pancreatic tumor mouse model of ${ }^{57} \mathrm{Co}$-DOTATOC, with a decrease in tumor uptake between $4 \mathrm{~h}$ and $24 \mathrm{~h}$ of more than $90 \%$. These results were not observed in our in vivo pharmacokinetic study with ${ }^{57} \mathrm{Co}$-DOTATATE and a similar AR42J tumor mouse model (Fig. 6). Tumor uptake between $4 \mathrm{~h}$ and $24 \mathrm{~h}$ decreased only to about $43 \%$, in good agreement with our in vitro efflux results.

The high level of lung uptake was somewhat surprising, although it has been seen in other studies with metal-labeled DOTATATE in mice (13). However, mouse lung tissue is known to express the SST4 receptor subtype (14), and DOTATATE has some affinity for this subtype (15). Furthermore, labeling of DOTATOC with Co rather than Ga or Y increases its SSTR4 affinity strongly, leading to lung uptake of the ligand (6). Hence, one could speculate that labeling of DOTATATE with $\mathrm{Co}^{2+}$ instead of typical trivalent radiometals could further increase the SSTR4 affinity, leading to increased lung uptake, although this notion was not investigated in the present study. Except for the lung uptake, the measured biodistribution of ${ }^{57} \mathrm{Co}$-DOTATATE was comparable to that found for ${ }^{111} \mathrm{In}$-DOTATATE by Froidevaux et al. (16).
As mentioned earlier, only a small fraction of the internalized cobalt or indium activity was translocated to the nuclei of the pancreatic tumor cells; the majority was found in the cytoplasm. It is generally well established that Auger electron emitters should be positioned in close vicinity to the genomic DNA to be maximally effective in cell killing, with high-linear energy transferlike effects (17). Such was not the case for the peptides used in the present study; for those peptides, no DNA binding was assumed to take place. Hence, the observed effects were not expected to be due to high-linear energy transfer "Auger effects" and, thus, may have been inferior to the effects of peptide receptor radionuclide therapy with $\alpha$ emitters. Nevertheless, both ${ }^{58 \mathrm{~m} C o-}$ DOTATATE and ${ }^{111}$ In-DOTATATE resulted in high DSB yields, with the former producing the largest number of DSBs $(P<0.05)$, and both compounds could effectively reduce the proliferation of AR42J cancer cells compared with the results for untreated controls. However, per cumulated decay from the radiopharmaceuticals during the incubation period, ${ }^{58 \mathrm{~m}} \mathrm{Co}$-DOTATATE was significantly more effective in cell killing than ${ }^{111}$ In-DOTATATE.

From the published theoretic radiation doses to the cell nucleus (and, thus, the DNA) per decay from the radionuclides used in the present study (i.e., the cellular $\mathrm{S}$ values (absorbed dose per unit cumulated activity) $(18,19)$ ), it can be calculated that ${ }^{58 \mathrm{~m}} \mathrm{Co}$ delivers approximately 2 and 6 times higher doses to the nucleus for decays taking place in the nucleus and the cytoplasm, respectively, than ${ }^{111} \mathrm{In}$. (The corresponding doses are approximately 2 and 11 times higher, respectively, for ${ }^{58 \mathrm{~m}} \mathrm{Co}$ than for ${ }^{58 \mathrm{~g}} \mathrm{Co}$. Hence, the dose contribution from this impurity, constituting $<2 \%$ at the end of synthesis, is negligible.) This calculation is in good agreement with the experimental findings. Compared with ${ }^{177} \mathrm{Lu},{ }^{58 \mathrm{~m}} \mathrm{Co}$ delivers approximately 3 times higher doses to the nucleus for decays taking place in the nucleus and the cytoplasm, respectively.

Furthermore, given the theoretic tumor-to-normal tissue dose rate ratios calculated by Uusijärvi et al. (7), ${ }^{58 \mathrm{~m}} \mathrm{Co}$ has tumor-tonormal tissue dose rate ratios that are approximately 15 and 11 times higher than those of ${ }^{111}$ In for activity located in the nucleus and the cytoplasm, respectively, of tumor cells. Hence, ${ }^{58 \mathrm{~m} C o-}$ DOTATATE theoretically should exhibit much less nonspecific toxicity in vivo in patients than ${ }^{111} \mathrm{In}$-DOTATATE; therefore, it should

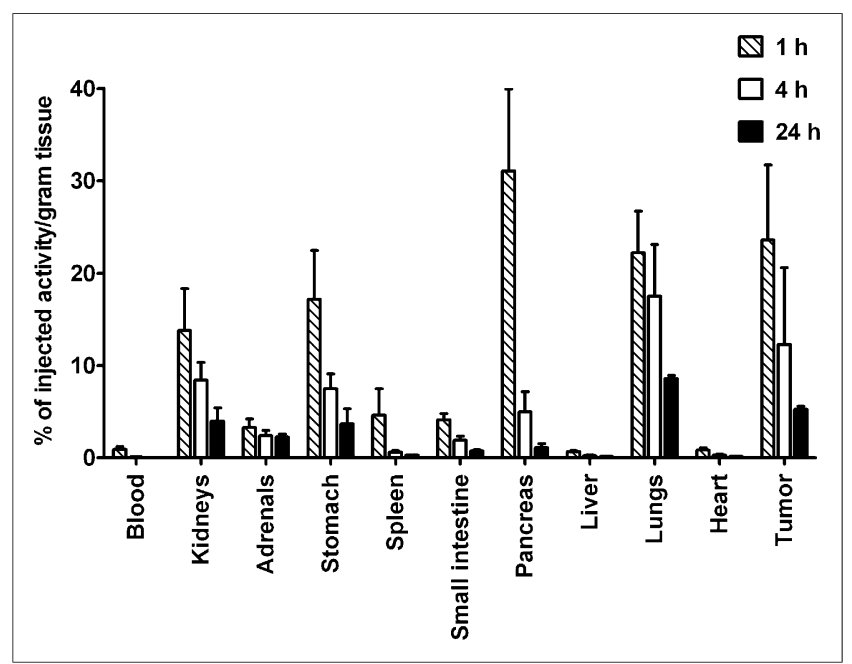

FIGURE 6. Biodistribution of ${ }^{57} \mathrm{Co}$-DOTATATE (105 $\pm 18 \mathrm{kBq} ; 32 \pm 5$ pmol of peptide) in AR42J tumor-bearing mice at 1, 4, and $24 \mathrm{~h}$ after injection (mean $\pm \mathrm{SD} ; n=3$ in each group). 
be possible to increase the injected activity considerably to achieve a higher radiation dose to the tumor without increasing the dose to the normal tissue.

At the lowest activity concentration, ${ }^{58 \mathrm{~m}}$ Co-DOTATATE was more effective in DSB formation and cell killing than $\beta^{-}$-emitting ${ }^{177} \mathrm{Lu}$-DOTATATE, but the opposite was found at the highest activity concentration. However, when the number of cumulated decays was considered, ${ }^{58 \mathrm{~m} C o-D O T A T A T E}$ was found to be significantly more effective in cell killing (Fig. 4). This finding is in good agreement with the previously mentioned theoretic radiation doses per decay: the long range of the $\beta^{-}$-particles from ${ }^{177} \mathrm{Lu}$ results in "wasted" energy deposited outside the cell (considered as single cells in the cellular $\mathrm{S}$ value formalism). On the other hand, radionuclide therapy of macroscopic tumors with $\beta^{-}$-emitting radionuclides relies mainly on cross-fire effects; in contrast, therapy with Auger electron emitters is based on localized energy depositions. Because almost no cross-fire takes place for cells growing in monolayers in vitro, as in the proliferation assay in the present study, a general prediction of the in vivo efficacy from the in vitro comparison described earlier is meaningless. However, for small micrometastases or single cells, for which cross-fire effects are insignificant, the comparison is valid. That is, in a future clinical setting, ${ }^{58 \mathrm{~m} C o-D O T A T A T E}$ could be an effective agent for eradicating circulating and disseminated tumor cells and micrometastases when used in combination with a long-range $\beta^{-}$-emitting radionuclide or another treatment modality for eradicating macroscopic tumor tissue. However, further studies of the therapeutic efficacy in vivo of ${ }^{58 \mathrm{~m}} \mathrm{Co}$-DOTATATE are required to determine the full potential of this promising radiopharmaceutical. If such studies become successful, then translation to clinical applications should be feasible. We recently calculated that it will be possible to produce more than $120 \mathrm{GBq}$ of ${ }^{58 \mathrm{~m}} \mathrm{Co}$ in $3 \mathrm{~h}$ with a small PET cyclotron (19). Hence, clinical applications with, for example, the administration of $18.5 \mathrm{GBq}$ per patient - as in a study using ${ }^{111} \mathrm{In}-\mathrm{DTPA}-$ octreotide (20)—should be achievable with ${ }^{58 \mathrm{~m}}$ Co-DOTATATE.

\section{CONCLUSION}

We evaluated the biologic effects of cobalt-labeled octreotide analogs targeting the somatostatin receptor in molecular imaging and Auger electron-based radionuclide therapy. All cobalt-labeled radioligands showed a high level of receptor-specific uptake both in vitro and in vivo in tumor-bearing mice. Overall, ${ }^{58 \mathrm{~m}} \mathrm{Co}-\mathrm{DOTA}-$ TATE showed better therapeutic effects in vitro than ${ }^{111}$ In-DOTATATE and ${ }^{177} \mathrm{Lu}$-DOTATATE, especially when the number of cumulated decays from the radiopharmaceuticals was considered. Hence, further in vivo studies of the therapeutic efficacy of this promising Auger electron-emitting radiopharmaceutical are warranted.

\section{DISCLOSURE}

The costs of publication of this article were defrayed in part by the payment of page charges. Therefore, and solely to indicate this fact, this article is hereby marked "advertisement" in accordance with 18 USC section 1734 . The bioimaging experiments reported in this article were performed at DaMBIC, a bioimaging research core facility, at the University of Southern Denmark. DaMBIC was established by an equipment grant from the Danish Agency for Science Technology and Innovation and by internal funding from the University of Southern Denmark. This work was sup- ported by the Lundbeckfonden Center of Excellence NanoCAN grant, the Region Syddanmarks Forskningspulje 2012 (j. nr.: 12/ 6433) and the Odense Universitetshospitals Forskningspulje 2010 (j. nr.: 2-41-4-00066-201). No other potential conflict of interest relevant to this article was reported.

\section{REFERENCES}

1. Reubi JC, Waser B, Schaer JC, Laissue JA. Somatostatin receptor sst1-sst5 expression in normal and neoplastic human tissues using receptor autoradiography with subtype-selective ligands. Eur J Nucl Med. 2001;28:836-846.

2. van Essen M, Krenning EP, Kam BL, de Jong M, Valkema R, Kwekkeboom DJ. Peptide-receptor radionuclide therapy for endocrine tumors. Nat Rev Endocrinol. 2009;5:382-393.

3. Heppeler A, Froidevaux S, Mäcke HR, et al. Radiometal-labelled macrocyclic chelator-derivatised somatostatin analogue with superb tumour-targeting properties and potential for receptor-mediated internal radiotherapy. Chem Eur J. 1999;5:1974-1981.

4. Kwekkeboom DJ, Bakker WH, Kooij PP, et al. $\left[{ }^{177} \mathrm{Lu}-\mathrm{DOTA}_{0}, \mathrm{Tyr}_{3}\right]$ octreotate:

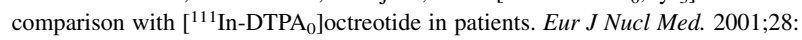
1319-1325.

5. Wild D, Schmitt JS, Ginj M, et al. DOTA-NOC, a high-affinity ligand of somatostatin receptor subtypes 2, 3 and 5 for labelling with various radiometals. Eur J Nucl Med Mol Imaging. 2003;30:1338-1347.

6. Heppeler A, André JP, Buschmann I, et al. Metal-ion-dependent biological properties of a chelator-derived somatostatin analogue for tumour targeting. Chemistry. 2008;14:3026-3034.

7. Uusijärvi H, Bernhardt P, Ericsson T, Forssell-Aronsson E. Dosimetric characterization of radionuclides for systemic tumor therapy: influence of particle range, photon emission, and subcellular distribution. Med Phys. 2006;33:32603269 .

8. Thisgaard H, Olesen ML, Dam JH. Radiosynthesis of ${ }^{55} \mathrm{Co}-$ and ${ }^{58 \mathrm{~m}} \mathrm{Co}-$ labelled DOTATOC for positron emission tomography imaging and targeted radionuclide therapy. J Labelled Comp Radiopharm. 2011;54:758-762.

9. Bailey KE, Costantini DL, Cai Z, et al. Epidermal growth factor receptor inhibition modulates the nuclear localization and cytotoxicity of the Auger electron-emitting radiopharmaceutical ${ }^{111}$ In-DTPA-human epidermal growth factor. J Nucl Med. 2007;48:1562-1570.

10. Jucha A, Wegierek-Ciuk A, Koza Z, et al. FociCounter: a freely available PC programme for quantitative and qualitative analysis of gamma-H2AX foci. Mutat Res. 2010;696:16-20.

11. Yardeni T, Eckhaus M, Morris HD, Huizing M, Hoogstraten-Miller S. Retroorbital injections in mice. Lab Anim (NY). 2011;40:155-160.

12. Olsen BB, Thisgaard H, Vogel S, et al. Novel radioisotope-based nanomedical approaches. Eur J Nanomed. 2013;5:181-193.

13. Schmitt A, Bernhardt P, Nilsson O, et al. Biodistribution and dosimetry of ${ }^{177} \mathrm{Lu}-$ labeled $\left[\mathrm{DOTA}_{0}, \mathrm{Tyr}_{3}\right.$ ] octreotate in male nude mice with human small cell lung cancer. Cancer Biother Radiopharm. 2003;18:593-599.

14. Varecza Z, Elekes K, Laszlo T, et al. Expression of the somatostatin receptor subtype 4 in intact and inflamed pulmonary tissues. $J$ Histochem Cytochem. 2009;57:1127-1137.

15. Reubi JC, Schar JC, Waser B, et al. Affinity profiles for human somatostatin receptor subtypes SST1-SST5 of somatostatin radiotracers selected for scintigraphic and radiotherapeutic use. Eur J Nucl Med. 2000;27:273-282.

16. Froidevaux S, Eberle AN, Christe $\mathrm{M}$, et al. Neuroendocrine tumor targeting: study of novel gallium-labeled somatostatin radiopeptides in a rat pancreatic tumor model. Int J Cancer. 2002;98:930-937.

17. Kassis AI. Molecular and cellular radiobiological effects of Auger emitting radionuclides. Radiat Prot Dosimetry. 2011;143:241-247.

18. Goddu SM, Howell RW, Lionel GB, Bolch WE, Rao DV. MIRD Cellular S Values. Reston, VA: Society of Nuclear Medicine; 1997.

19. Thisgaard H, Elema DR, Jensen M. Production and dosimetric aspects of the potent Auger emitter Co-58m for targeted radionuclide therapy of small tumors. Med Phys. 2011;38:4535-4541.

20. Delpassand ES, Sims-Mourtada J, Saso H, et al. Safety and efficacy of radionuclide therapy with high-activity In-111 pentetreotide in patients with progressive neuroendocrine tumors. Cancer Biother Radiopharm. 2008;23:292-300.

21. WWW table of radioactive isotopes (version 2.1). LBNL Isotopes ProjectLUNDS Universitet website. http://ie.lbl.gov/toi/. Published 2004. Accessed May 13, 2014. 